\title{
ANALYSIS OF DNA PLOIDY AND S-PHASE FRACTION IN RELATION TO DEVELOPMENT OF ORAL SQUAMOUS CELL CARCINOMA: AN EXPERIMENTAL STUDY
}

\author{
Ahmed M. Hussein*, Sahar M. El-Sheikh ${ }^{* *}$, Mahmoud A. Attia*** \\ Omneya R. Ramadan ${ }^{* * * *}$ Enas M. Omar ${ }^{* * * * *}$ and Ahmed H. Gaber ${ }^{* * * * * *}$
}

\begin{abstract}
Introduction: Cancer is a serious public health problem in many parts of the world; oral squamous cell carcinoma was the $11^{\text {th }}$ most common malignant neoplasm in human papulation. The hamster cheek pouch carcinogenesis model is a well-known animal system that closely mimics the development of premalignant and malignant lesions in human oral cancer. The expressions of cancerization process in this model using DNA ploidy and S-phase fraction is the point of interest.
\end{abstract}

Aim of the study: This research was carried out to study the analysis of DNA ploidy and S-phase fraction in relation to development of oral squamous cell carcinoma during hamster cheek pouches carcinogenesis process induced by DMBA.

Material and methods: A total of 50 young gold Syrian hamsters distributed into groups as follows: 2 normal animals examined for the normal histology of the cheek pouch mucosa and 48 animals divided into; group I, as a control group $(n=12)$, in which pouches were painted with a heavy mineral oil only; group II, were painted with DMBA mixed in a heavy mineral oil $(n=36)$. The examined animal tissue utilized for flow cytometry analysis to obtain DNA ploidy and S-phase fraction development during carcinogenesis process.

Results: The flow cytometric analysis of DNA content demonstrated a significant role in carcinogenesis process in oral squamous cell carcinoma. Moreover, they provided a significant analysis in the proliferation and activity of the cancer cells as measured by the S-phase fraction activity.

Conclusions: The combinatorial DNA content analysis involving general ploidy and S-phase fraction have potential for support in the early diagnosis; during the development of oral squamous cell carcinoma.

KEY WORDS: DNA ploidy, S-phase fraction, Flow cytometry, Squamous cell carcinoma.

\footnotetext{
*Lecturer of Oral and Maxillofacial Pathology Department, Faculty of Oral and Dental Medicine, SVU, Qena, Egypt.

** Dean of Faculty of Dentistry, Professor of Oral Pathology, Faculty of Dentistry, Alexandria University, Alexandria, Egypt.

*** Assistant Professor of Oral Pathology, Department of Oral Pathology, Faculty of Dental Medicine, Al-Azhar University,

Assiut Branch, Egypt.

**** Assistant Professor of Oral Pathology, Faculty of Dentistry, Alexandria University, Alexandria, Egypt.

******* Lecturer of Oral Pathology, Faculty of Dentistry, Alexandria University, Alexandria, Egypt.

****** Lecturer of Oral Pathology, Department of Oral Pathology, Faculty of Dental Medicine, Al-Azhar University, Assiut

Branch, Egypt
} 


\section{INTRODUCTION}

Oral cancer accounts for $7 \%$ of all new cancer cases ${ }^{(1)}$. Squamous cell carcinoma is the most common malignant tumor that affect the oral cavity worldwide which representing more than $90 \%$ of oral carcinomas (2). The simultaneous and sequential development of the premalignant and malignant oral lesions is the result of progressive genotypic and phenotypic alterations associated with field cancerization ${ }^{(3)}$.

The DNA analysis field is a prominent area of interest as chromosomal alterations represent one of the most characteristic feature of neoplasia ${ }^{(4)}$. It is widely accepted that the accumulation of genetic aberrations is necessary for malignant progression. Among them, mutations affecting normal chromosome segregation may lead to DNA aneuploidy and abnormal nuclear content ${ }^{(5)}$. DNA ploidy describes the nuclear DNA contents and the alteration in DNA content from the diploid value is referred to as aneuploid, and it is accepted as an indicator for malignancy ${ }^{(6)}$. Cells are considered as having aneuploid DNA content when their DNA does not reach its normal diploid value or when they exceed the tetraploid value ${ }^{(7)}$. Different malignant tumors in human exhibited different grades of aneuploidy that mostly correlated with the tumors histopathological behavior ${ }^{(8)}$. The non-diploid DNA status was tightly linked to unfavorable cancer features; such as high grade, advanced tumor stage and positive nodal stage ${ }^{(9)}$.

Synthesis Phase Fraction (SPF) is also correlated with tumors behavior. Generally, tumors with high SPF have demonstrated more aggressive behavior and poorer prognosis ${ }^{(10)}$. The DNA ploidy analysis and S-phase fraction measurement can be easily performed on both fresh and formalin-fixed tissue specimens, and have become a useful as diagnostic and prognostic tools to be applied on solid malignant tumors in general and particularly on oral cancer ${ }^{(11)}$.

Flow cytometry analysis is a fast tool for estimation of the DNA status and the cellular proliferation status of the tumor. It enables to determine the DNA content in neoplasm cells and provides 2 functional factors; the DNA ploidy and the SPF in the form of DNA histograms ${ }^{(12)}$. In most normal cell populations, the majority of the cells are in $\mathrm{G} 0 / \mathrm{G} 1$ phase of the cell cycle. These cells have a normal diploid (2N) DNA content. A small number of cells are normally seen in the DNA synthesis phase and in the $\mathrm{G} 2$ and $\mathrm{M}$ phases of the cycle. Cells in the $\mathrm{G} 2$ and $\mathrm{M}$ phases have a tetraploid (4N) DNA content, while S-phase cells containing amounts of DNA between $2 \mathrm{~N}$ and $4 \mathrm{~N}$ values ${ }^{(13)}$.

The extrapolation of data from experimentally induced tumors to sporadic human cancers should be cautious. The hamster cheek pouch (HCP) is certainly an excellent model to study genetic changes in the carcinogenesis process, and particularly those involved in the field cancerization phenomenon ${ }^{(9)}$. The HCP is the best well-known animal carcinogenesis model that closely mimics the oral cancer development of premalignant and malignant lesions as in humans ${ }^{(14)}$. Although the carcinogen is applied on the surface of the whole buccal pouch, the process of carcinogenesis is not uniform. The severity of the lesions increases with time. These features render the model of HCP oral cancer ideal to understand the oral carcinogenesis process ${ }^{(15)}$

Carcinogenesis induced by 7, 12-dimethylbenz[a] anthracene (DMBA) in the HCP shows extensive similarities to the human oral squamous cell carcinoma $(\mathrm{OSCC})^{(16)}$. The DMBA is a potent specific carcinogen known to induce multistep carcinogenesis, developing by a sequence of hyperplasia, dysplasia and carcinoma (17). Exophytic neoplasms resemble the human oral verrucous carcinomas which grow toward the pouch lumen in terms of hyperkeratinization. However, endophytic tumors appear later and infiltrate the thickness of the pouch wall. Histologically, they resemble human OSCC, exhibiting different grades of atypia and differentiation ${ }^{(18)}$.

Thus, the purpose of this study was the investigation of the DNA ploidy and SPF during DMBA induced OSCC in the HCP by flow cytometric analysis. 


\section{MATERIALS AND METHODS}

The study included 50 young pathogen free Syrian hamsters (males only), 6-7 weeks old, weighing approximately 80-100 g each. Hamsters were purchased from Theodor Bilharz Research Institute, Cairo, Egypt. They were housed in the experimental animal unite of the Oral Pathology Research Institute, Faculty of Oral and Dental Medicine, South Valley University. The hamsters were housed as 6 per cage in a show polypropylene cages; in a room with controlled temperature and a relative humidity. They were fed ad libitum and kept on a light/darkness cycle of 12/12 h. All animal procedures were performed in accordance with the National Institute of Health Guide for the Care and Use of Laboratory Animals ${ }^{(19)}$. The materials used in this study were DMBA (Sigma, USA), and The Cycle TEST ${ }^{\mathrm{TM}}$ PLUS DNA Reagent Kit (BD Biosciences).

After 2 weeks of adaptation and feeding, 2 animals were sacrificed and the normal oral mucosa was histologically examined. The remaining 48 animals were randomly divided into 2 groups as following: group I (as a control group, $n=12$ ); the right cheek pouches of these animals were painted with a heavy mineral oil only. Group II $(n=36)$; the animals were submitted to a standard carcinogenesis protocol that involves the topical application of $0.5 \%$ DMBA mixed in a heavy mineral oil, on the right cheek pouch 3 times/week over a 6-month period using number 4 sable-hair brush ${ }^{(20)}$.

At 4, 8, 12,16,20 and 24 weeks' intervals, 2 animals from the control group and 6 animals from group II were killed by inhalation of an overdose of sulfuric ether. Thirty minutes prior to killing the animals, they were given an intraperitoneal injection of a solution (5 $\mathrm{mg} / \mathrm{ml}$ ) of 5-bromo-2-deoxiuridine (BrdU) in saline solution at a dose of $0.08 \mathrm{mg} \mathrm{BrdU/g}$ body weight. The right cheek pouch of each animal was opened longitudinally and excised through the skin wall and directly immersed in 10\% neutral-buffered formalin for at least $24 \mathrm{~h}$ for fixation.
Tumor tissue from each animal was cut into 3 sections of $50 \mu \mathrm{m}$ thickness and transferred for DNA cytometric analysis of DNA ploidy and SPF in the Flow Cytometry Unit, Clinical Pathology Department, South Egypt Cancer Institute. Single nuclear suspensions were prepared by filtering through a $50 \mu \mathrm{m}$ nylon mesh. Sample with the stained nuclei were analyzed using a FACS Calibur Flow Cytometer (Becton Dickinson Biosciences, San Jose, California USA). Cell fit software was used to acquire and analyze the obtained data. The fluorescence signals from at least 50.000 nuclei were plotted and displayed as a frequency histogram. The DNA ploidy, DNA Index (DI) and SPF were taken as flow cytometric variables. The percentages of the cell cycle phases as well as the DNA indices of the aneuploid clones were calculated using the mod-fit software package. The DNA diploid cell numbers of normal right HCP were used as a reference standard for the identification of DNA aneuploid clones.

Furthermore, a portion of the tissue samples that had the evident lesions were dissected and processed for paraffin embedding procedure. One section from each block was cut at $5 \mu \mathrm{m}$ thickness and stained with Hematoxylin and Eosin (H\&E) to identify its histological categories as hyperplasia, dysplasia, carcinoma in situ or carcinomas. Also; to assure that the tumor tissue constitutes $>70 \%$ with minimal necrotic and hemorrhagic foci. The control areas were taken from animals' cheek pouches treated with mineral oil alone.

The relative DNA content was obtained by calculating the ratio of abnormal (aneuploid) G0/ G1 peak to the mean channel number of normal (diploid) G0/G1 peak. The ratio is referred to as DI. In the present study, the DI for diploid tumors ranged from 0.95 to 1.05 , therefore, samples were considered aneuploid if their DI was less than 0.95 (hypodiplod) or more than 1.05 (hyperdiploid). The DI was statistically calculated and recorded by the computer calculation program for DNA analysis. All 
specimens had a $\mathrm{G} 0 / \mathrm{G} 1$ peak coefficient of variation of no more than $4 \%$. The SPF was estimated as percentage of cells occupying the region between the mean channel number for $\mathrm{G} 0 / \mathrm{G} 1$ and that of G2/M. The cut off for the SPF was set as the mean \pm 2 standard deviation (SD) and considered as either being low or high.

Data was statistically analyzed in terms of mean $\pm \mathrm{SD}$, median and range, or frequencies (number of cases) and percentages when appropriate. Comparison of numerical variables between the study groups were done using Mann Whitney U test for independent samples when comparing control and experimental animals' tissues and Kruska Wallis test when comparing the flow cytometric analysis in relation to tumor grades. For comparing categorical data, Chi square $(\chi 2)$ test was performed.

\section{RESULTS}

The OSCC development had a range of variation between the study animals as following: In control group I, the HCPs were painted with a mineral oil only, no clinico-pathological changes were developed during the whole study period. The lining epithelium of HCP showed normal appearance. Only few hamsters in this group exhibited hyperkeratosis in the last study weeks as the only histopathological change observed in this group.

In group II, the animals' cheek pouches were treated with $0.5 \%$ DMBA. After 4 weeks, no detectable clinico-pathological changes in most of the animals were seen, except for small white patches areas were observed in 2 out of 6 hamsters. The lining epithelium of the examined HCPs revealed areas of focal thickening without any cellular atypia. At 8 weeks, the HCPs started to show non-scrapable erythroleukoplakic lesions with sloughing of the mucosa. The epithelial alterations started to appear with areas of exophytic and endophytic proliferation of the epithelial lining that showed mild dysplasia.

At week 12, most of the HCPs were presented clinically with diffuse erythematous areas, some exhibited evident ulcerative lesions. The histological examination of the HCPs revealed thickened hyperkeratotic stratified squamous epithelium. Top to bottom dysplastic changes indicating carcinoma in situ were noted in 3 animals. One animal showed areas of micro invasion of the malignant epithelial cells into the underlying connective tissue with evident keratin formation. After 16 weeks, well defined exophytic nodules developed in some animals. The examined HCPs showed invasive well differentiated OSCC.

By the end of week 20 of the carcinogenesis process, well developed oral tumors were observed, some appeared as exophytic granular masses (Figure 1), while others showed endophytic ulcers with raised margins and necrotic floor. The examined HCPs lining epithelium showed features of moderately-differentiated OSCC. Massive areas of necrosis, inflammation and increased vascularity were also seen. After 24 weeks, the HCPs of the remaining last animals developed huge fungating oral masses with areas of necrosis and extensive tissue destruction. The histological examination of the HCPs revealed moderate to poorly differentiated OSCC (Figure 2). In group II, different grades of oral tumor were developed in 22 out of 36 examined animals $(61.11 \%)$. The oral lesions varied from carcinoma in situ to poorly differentiated OSCC. The difference in cancer incidence was highly statistically significant $(\mathrm{p}<0.0001)$ when comparing between group I and group II.

\section{DNA Content Analysis}

The normal HCPs mucosa were considered as standard that showed a single diploid peak (reference peak) representing G0/G1 cells $(2 \mathrm{~N})$. They had shown no cells in the S-phase or at $\mathrm{G} 2 / \mathrm{M}$ peak (Figure 3). A total remaining number of $48 \mathrm{HCPs}$ were analyzed by DNA FCM. The whole animals in group I were diploid as the normal diploid peak. Sixteen hamsters (44.44\%) of group II among 36 animals were showed aneuploid DNA pattern with considerable variation in DNA content. The DNA 


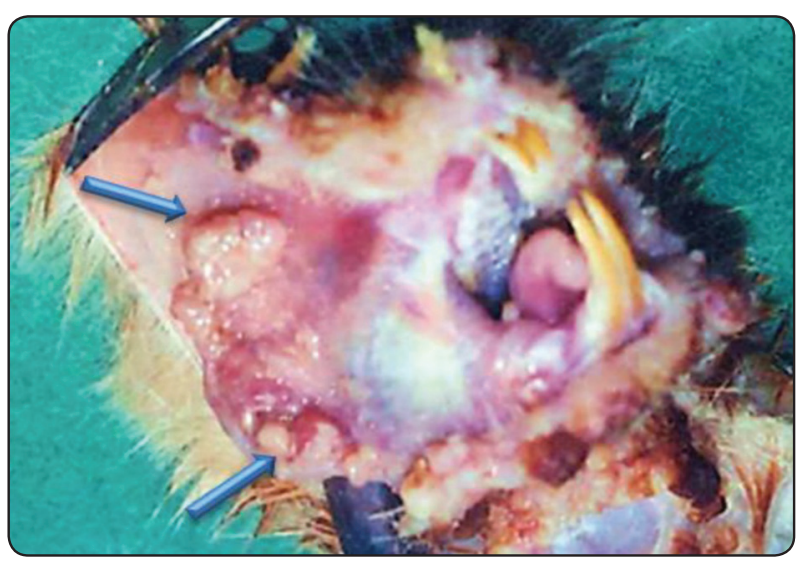

Fig. (1): The HCP Showing Exophytic Masses with Granular Surface at 20 Weeks, Group II (Blue Arrows).

aneuploidy lesions appeared from the 12 week of carcinogenesis process as one animal at 12 weeks, 4 animals at 16 weeks, 5 animals at 20 weeks and all 6 animals of 24 weeks (Table 1).

TABLE (1): DNA Ploidy in Group II Concerning the Histopathological Finding.

\begin{tabular}{|c|c|c|c|}
\hline W. & No. & Histopathological Finding & $\begin{array}{c}\text { Diploid/ } \\
\text { Aneuploid }\end{array}$ \\
\hline \multirow{2}{*}{$4 \mathrm{~W}$} & 6 & Focal Epith. Thickening & $6 / 0$ \\
\hline \multirow{2}{*}{$8 \mathrm{~W}$} & 6 & $\begin{array}{c}\text { Mild to Moderate Epith. } \\
\text { Dysplasia }\end{array}$ & $6 / 0$ \\
\hline \multirow{2}{*}{$12 \mathrm{~W}$} & 3 & Carcinoma In Situ & $3 / 0$ \\
\cline { 2 - 5 } & 1 & Early Invasive Carcinoma & $0 / 1$ \\
\hline \multirow{2}{*}{$16 \mathrm{~W}$} & 6 & Well Differentiated OSCC & $2 / 4$ \\
\hline \multirow{2}{*}{$20 \mathrm{~W}$} & 6 & Moderate Differentiated OSCC & $1 / 5$ \\
\hline \multirow{2}{*}{$24 \mathrm{~W}$} & 3 & Moderate Differentiated OSCC & $0 / 3$ \\
\cline { 2 - 5 } & 3 & Poorly Differentiated OSCC & $0 / 3$ \\
\hline
\end{tabular}

The diploid lesions showed a single diploid peak at $(2 \mathrm{~N})$ similar to that of the reference peak. In addition, in some cases $\mathrm{G} 2 / \mathrm{M}$ cells were also identified as a small peak at $(4 \mathrm{~N})$ that contained less than $15 \%$ of whole cells (Figure 4). The aneuploid tumors showed an additional peak with its main

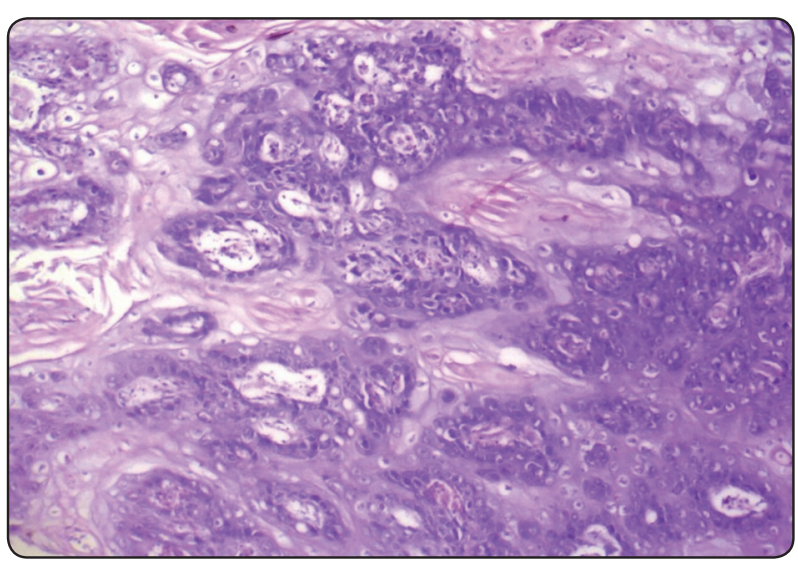

Fig. (2): A Photomicrograph Showing Poorly Differentiated OSCC with Evident Dysplastic Criteria at 24 Weeks, Group II, (H\&E X400).

channel. Non-diploid tumors were further classified into: 12 hyperdiploid cases by the presence of additional stem line(s) to the right of G0/G1 diploid peak with DI ranged from 1.06 to 1.47 with a mean of 1.13 (Figure 5), and 4 hypodiploid cases by the presence of additional stem line(s) to the left of G0/ G1diploid peak with DI ranged from 0.79 to 0.88 with a mean of 0.83 (Figure 6). The difference in the ploidy state (diploid and aneuploid DNA pattern) between group I and group II was statistically highly significant $(\mathrm{p}=0.001)$. Also, the significant difference between diploid and aneuploid group II tumors was highly significant $(\mathrm{p}=0.001)$.

The SPF values calculated for the cell cycles of the diploid group I ranged between $0 \%$ and $2.67 \%$ with a mean of $1.34 \%$. In group II, SPF values ranged between $1.57 \%$ and $23.94 \%$ with a mean of $13.65 \%$ in diploid lesions. While the SPF of the aneuploid malignant tumors ranged between $8.3 \%$ and $48.7 \%$ with a mean of $16.87 \%$. The studied cases, of diploid group I had low SPF (number of cells in SPF were less than $1.34 \%)$. While $50 \%(10 / 20)$ of diploid group II had high SPF (numbers of cells in SPF were equal or more than $13.65 \%$ ), and 10 cases (50\%) had low SPF. In the aneuploid group II lesions nearly $31.25 \%$ (5/16) of cases were low SPF (number of cells in SPF were less than $16.87 \%$ ), and 11 cases nearly $68.75 \%$ were high (Table 2). There is a high significant difference in 
TABLE (2) Correlation of Carcinogenesis Process Development Weeks with Flow Cytometric Finding (DNA Ploidy and S-Phase Fraction).

\begin{tabular}{|c|c|c|c|c|}
\hline \multirow{2}{*}{ W. } & \multirow{2}{*}{ DNA Ploidy } & \multirow{2}{*}{ No. } & \multicolumn{2}{|c|}{ SPF } \\
\hline & & & Low & High \\
\hline \multirow{2}{*}{$4 \mathrm{~W}$} & \multirow{2}{*}{ Diploid } & 6 & 5 & 1 \\
\hline & & $100 \%$ & $83.33 \%$ & $16.77 \%$ \\
\hline \multirow{2}{*}{$8 \mathrm{~W}$} & \multirow{2}{*}{ Diploid } & 6 & 4 & 2 \\
\hline & & $100 \%$ & $66.66 \%$ & $33.33 \%$ \\
\hline \multirow{4}{*}{$12 \mathrm{~W}$} & \multirow{2}{*}{ Diploid } & 5 & 1 & 4 \\
\hline & & $83.33 \%$ & $20 \%$ & $80 \%$ \\
\hline & \multirow{2}{*}{ Aneuploid } & 1 & 1 & 0 \\
\hline & & $16.77 \%$ & $100 \%$ & $0 \%$ \\
\hline \multirow{4}{*}{$16 \mathrm{~W}$} & \multirow{2}{*}{ Diploid } & 2 & 0 & 2 \\
\hline & & $33.33 \%$ & $0 \%$ & $100 \%$ \\
\hline & \multirow{2}{*}{ Aneuploid } & 4 & 2 & 2 \\
\hline & & $66.66 \%$ & $50 \%$ & $50 \%$ \\
\hline \multirow{4}{*}{$20 \mathrm{~W}$} & \multirow{2}{*}{ Diploid } & 1 & 0 & 1 \\
\hline & & $16.77 \%$ & $0 \%$ & $100 \%$ \\
\hline & \multirow{2}{*}{ Aneuploid } & 5 & 1 & 4 \\
\hline & & $83.33 \%$ & $20 \%$ & $80 \%$ \\
\hline \multirow{2}{*}{$24 \mathrm{~W}$} & \multirow{2}{*}{ Aneuploid } & 6 & 1 & 5 \\
\hline & & $100 \%$ & $16.77 \%$ & $83.33 \%$ \\
\hline \multirow{4}{*}{ Total } & \multirow{2}{*}{ Diploid } & 20 & 10 & 10 \\
\hline & & $55.56 \%$ & $50 \%$ & $50 \%$ \\
\hline & \multirow{2}{*}{ Aneuploid } & 16 & 5 & 11 \\
\hline & & $44.44 \%$ & $31.25 \%$ & $68.75 \%$ \\
\hline
\end{tabular}

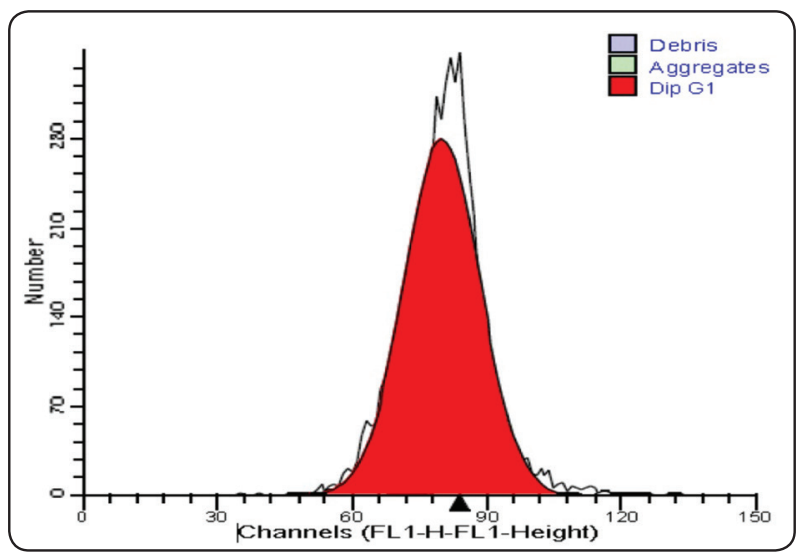

Fig. (3): DNA Frequency Histogram of Diploid Standard (Normal HCP Mucosa), Showing Single G0/G1 Peak and No SPF Cells.

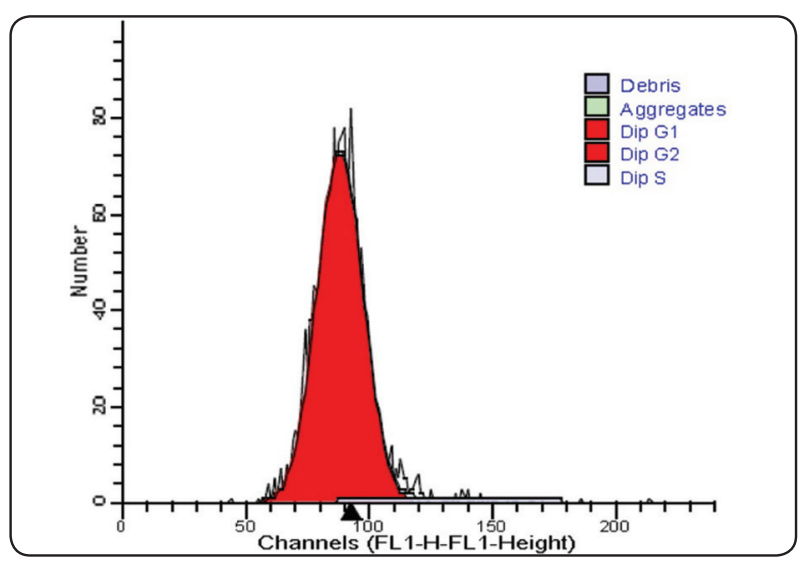

Fig. (4): DNA Frequency Histogram of Diploid Group II Tumor, Showing Single G0/G1 Peak and Low SPF Cells (5.45\%).

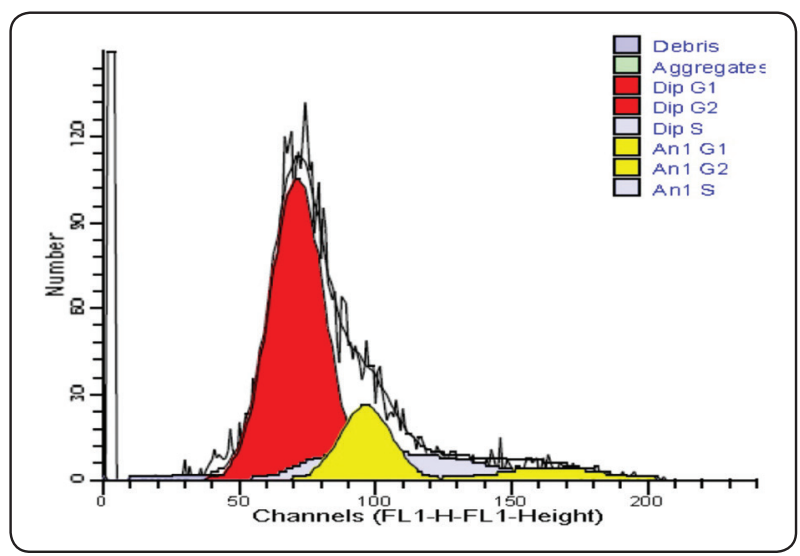

Fig. (5): DNA Frequency Histogram of Aneuploid Malignant Tumors Showing Hyperdiploid (DI= 1.35), Group II Tumor and High SPF Cells (17.24\%).

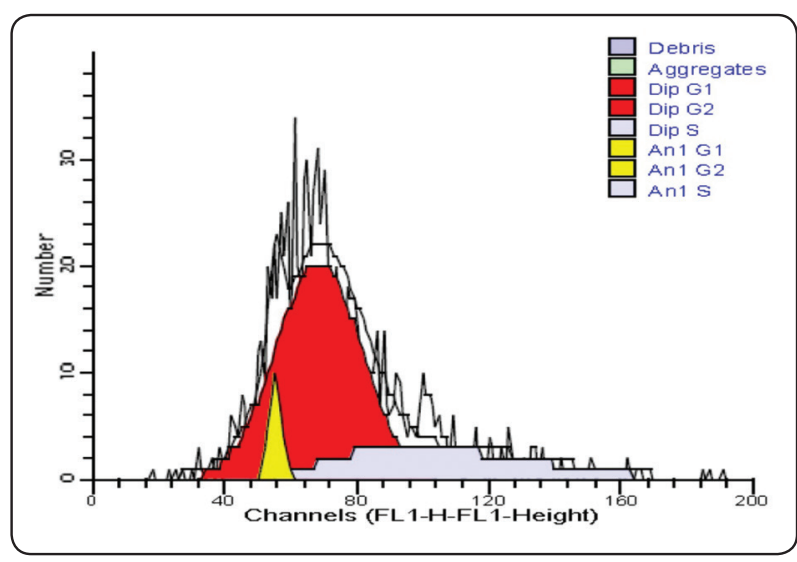

Fig. (6): DNA Frequency Histogram of Aneuploid Malignant Tumors Showing Hypodiploid (DI= 0.81), Group II Tumor and High SPF Cells (23.79\%). 
the mean SPF value of group I and group II animals' lesions $(p=0.002)$ and no significant difference between diploid versus aneuploid lesions of group II $(p=0.514)$. Low significant relationship $(p=0.02)$ was detected between DNA ploidy and SPF of the group II tumors. The results revealed that $68.75 \%$ of the aneuploid tumors versus $31.25 \%$ of the diploid tumors had high SPF.

\section{DISCUSSION}

In the present study, the difference in cancer incidence was highly statistically significant. Different grades of oral tumor were developed in $66.11 \%$ of animals during the study period. In agreement with the current work, Li et al. ${ }^{(21)}$ reported that development of OSCC was seen in the examined HCPs as $76.9 \%$. In addition, Mariadoss et al. ${ }^{(22)}$ found that $100 \%$ tumor formation after 14 weeks of painting DMBA alone on the hamster' buccal pouches. These results did not differ much from other studies done by Rajasekaran et al. ${ }^{(23)}$. This goes with the results of the present research, where all animals were sacrificed after 16 weeks of the study developed OSCC. In contrast, reduction in the process of carcinogenesis induced by DMBA was reported when other drugs were given as a treatment during the carcinogenesis process (24). Moreover, Patil et al. ${ }^{(25)}$ reported that more tissue resistance to DMBA induced carcinogenesis was noticed in the old hamsters more than the young ones. The current study was applied on young 6-7 weeks old pathogen-free adult Syrian hamsters. Further support can be derived from that the cancer incidence had a range of variation between the studies groups as $66.67 \%$ in animals only were painted with DMBA. The cancer incidence and development decreased with chemoprevention and chemotherapy treatment as the result of Hussein et al. study ${ }^{(26)}$.

DNA ploidy has proven to be a useful prognostic indicator in a variety of neoplasms ${ }^{(27)}$. Our results support that the DNA aneuploidy is a very early incident in detection of oral carcinogenesis. When abnormal DNA amounts reach certain levels, they can be detected by the flow cytometric analysis. This method has already been applied to the study of oral cancer and has shown an association between aneuploidy and histological dysplasia and the risk of malignant transformation. The detection of aneuploidy in nondysplastic tumors has been of even greater significance as the result of Sudbo et al. stated ${ }^{(28)}$. This observation goes with the results of Raimondi et al. ${ }^{(9)}$ that moves forward in the possibility of detecting aneuploid cells in the cancerization field before the appearance of histological lesions. Alterations in karyotype of HCP cells as early as 2 weeks after the beginning of tumor induction were reported in different genetic studies ${ }^{(29,30)}$.

The present study reported 16 hamsters (44.44\%) of group II among 36 animals were showed aneuploid DNA pattern. The significant difference between diploid and aneuploid group II tumors was highly significant $(\mathrm{p}=0.001)$. The discrepancy can be explained by the duration of the current study extending to 24 weeks and development of moderate to poor OSCC in more than 10 animals. A higher incidence of aneuploidy among OSCC tumors was reported by Das et al. ${ }^{(31)}$. In agreement with our results, some researchers showed that the incidence of aneuploidy among their series of OSCC increase in moderate tumor grades ${ }^{(32)}$. It was generally observed that used OSCC fresh tissues as in this study reported a higher incidence of aneuploidy than those who used fresh frozen tumor tissues OSCC samples ${ }^{(33)}$. Furthermore, authors observed that DNA ploidy is heterogeneous within squamous cell carcinoma of the oral cavity and the incidence of aneuploidy was very high when multiple tissue samples from each tumor were analyzed ${ }^{(34)}$. Also, recently Kusama et al. ${ }^{(35)}$ indicated that the DI of DNA ploidy may be able to predict the prognoses of cancer patients with greater accuracy. The observation is consistent with findings which indicating that hypodiploidy is rarely found during the early stages of carcinogenesis, presumably because of its lethality at the cellular level ${ }^{(36)}$. Moreover, in agreement with Coley et al. ${ }^{(37)}$ we observed that diploid tumors showed the lowest 
SPF, indicative of a lower proliferation rate and less aggressive behavior than hyper- and hypodiploid lesions.

The SPF represented a variable related to any proliferating cell population so it represented one of the biomarkers of malignancy. This study showed that aneuploid lesions had higher SPF (68.75\%) versus the diploid one (31.25\%) but with no significant difference. This result may be because that there was no variation in numbers of SPF of diploid and aneuploid group II animals. Comparable results were obtained by a study of Zahran et al. ${ }^{(38)}$ who found that all diploid tumors had S-phase percentage less than those of the lowest aneuploid cell line but with no significant difference. In contrast several authors reported, that the SPF was significantly higher in aneuploid OSCC tumors than in diploid carcinomas and it a better indicator of tumor aggressiveness and predicting disease prognosis than the DNA ploidy ${ }^{(39,40)}$.

\section{CONCLUSION}

The results of the present study indicated that the DNA content analysis involving general ploidy and S-phase fraction is a powerful key indicator for tumor activity and malignancy during development of oral squamous cell carcinoma.

\section{REFERENCES}

1. Simard EP, Torre LA, Jemal A. International trends in head and neck cancer incidence rates: differences by country, sex and anatomic site. Oral Oncol. 2014;50:387-403.

2. Ranganathan K, Kavitha L. Oral epithelial dysplasia: classifications and clinical relevance in risk assessment of oral potentially malignant disorders. J Oral Maxillofac Pathol. 2019;23:19-27.

3. Tabor M, Brakenhoff H, van Houten VM, Kummer JA, Snel MH, Snijders PJ, et al. Persistence of genetically altered fields in head and neck cancer patients: biological and clinical implications. Clin Cancer Res. 2001;7:1523-32.

4. Brenner JC, Chinnaiyan AM. Translocations in epithelial cancers. Biochem Biophys Acta. 2009;1796:201-15.
5. Ghadimi BM, Sackett DL, Difilippantonio MJ, Schrock E, Neumann T, Jauho A, et al. Centrosome amplification and instability occurs exclusively in aneuploid, but not in diploid colorectal cancer cell lines, and correlates with numerical chromosomal aberrations. Genes Chromosomes Cancer. 2000;27:183-90.

6. Taylor AM, Shih J, Ha G, Gao GF, Zhang X, Berger AC et al. Genomic and functional approaches to understanding cancer aneuploidy. Cancer Cell. 2018;9:676-89.

7. Raimondi A, Cabrini R, Itoiz ME. Ploidy analysis of field cancerization and cancer development in the hamster cheek pouch carcinogenesis model. J Oral Pathol Med. 2005;34:227-31

8. Lundgren C, Auer G, Frankendal B, Moberger B, Nilsson B, Nordstrom B, et al. Nuclear DNA content, proliferative activity, and p53 expression related to clinical and histopathologic features in endometrial carcinoma. Int J Gynecol Cancer. 2002;12:110-8

9. Lennartz M, Minner S, Brasch S, Wittmann H, Paterna L, Angermeier K, et al. The combination of DNA ploidy status and PTEN/6q15 deletions provides strong and independent prognostic information in prostate cancer. Clin Cancer Res. 2016;22:2802-11.

10. Driemel O, Maier H, Kraft K, Haase S, Hemmer J. Flow cytometric DNA ploidy in salivary gland tumors. Oncol Rep. 2005;13:161-5.

11. Gupta N, Kumar R. Role of flow cytometry in diagnostic pathology. Jk Sci. 2010;12:110-1.

12. Driemel O, Kraft K, Hemmer J. Flow cytometric Sphase fraction contributes to diagnosis of diploid malignant salivary gland tumors. Int J Oral Maxillofac Surg. 2006;35:947-50

13. Hawley TS, Hawley RG. Flow cytometry protocols. New York, NY: Humana Press; 2018.

14. Suresh K, Manoharan S, Vijayaanand MA, Sugunadevi G. Chemopreventive and antioxidant efficacy of (6)-paradol in 7,12-dimethylbenz(a)anthracene induced hamster buccal pouch carcinogenesis. Pharmacol Rep. 2010;62:1178-85.

15. Bowen JM, Gibson RJ, Keefe DM. Animal models of mucositis: implications for therapy. J Support Oncol. 2011;9:161-8.

16. Nagini S, Kowshik J. The hamster buccal pouch model of oral carcinogenesis. Methods Mol Biol. 2016;1422:341-50.

17. Chen YK, Lin LM. DMBA-induced hamster buccal pouch 
carcinoma and VX2-induced rabbit cancer as a model for human oral carcinogenesis. Expert Rev Anticancer Ther. 2010;10:1485-96.

18. Monti-Hughes A, Aromando RF, Perez MA, Schwint AE, Itoiz ME. The hamster cheek pouch model for field cancerization studies. Periodontol 2000. 2015;67:292-311.

19. National Research Council (US) Committee for the Update of the Guide for the Care and Use of Laboratory Animals. Guide for the Care and Use of Laboratory Animals. 8th ed. Washington (DC): National Academies Press (US); 2011.

20. Shklar G. Development of experimental oral carcinogenesis and its impact on current oral cancer research. J Dent Res. 1999; 78:1768-72.

21. Li N, Chen X, Liao J, Yang G, Wang S, Josephson Y, et al. Inhibition of 7,12-dimethylbenz[a] anthracene (DMBA)-induced oral carcinogenesis in hamsters by tea and curcumin. Carcinogenesis. 2002;23:1307-13.

22. Mariadoss AV, Kathiresan S, Muthusamy R, Kathiresan S. Protective effects of [6]-paradol on histological lesions and immunohistochemical gene expression in DMBA induced hamster buccal pouch carcinogenesis. Asian Pac J Cancer Prev. 2013;14:3123-9.

23. Rajasekaran D, Manoharan S, Prabhakar MM, Manimaran A. Enicostemma littorale prevents tumor formation in 7,12-dimethylbenz(a)anthracene-induced hamster buccal pouch carcinogenesis. Hum Exp Toxicol. 2015;34:911-21.

24. Rajasekar M, Suresh K, Sivakumar K. Diosmin induce apoptosis through modulation of STAT-3 signaling in 7,12 dimethylbenz(a)anthracene induced hamster buccal pouch carcinogenesis. Biomed Pharmacother. 2016;83:1064-70.

25. Patil S, Rao R, Raj T. Animal models--decoding the molecular biology of oral cancer. J Contemp Dent Pract. 2015;16:i-ii.

26. Hussein A, El-Sheikh S, Darwish Z, Hussein K, Gaafar A. Effect of genistein and oxaliplatin on cancer stem cells in oral squamous cell carcinoma: an experimental study. ADJ. 2018;3:117-23.

27. Bremmer JF, Brakenhoff RH, Broeckaert MA, Belien JA, Leemans CR, Bloemena E. Prognostic value of DNA ploidy status in patients with oral leukoplakia. Oral Oncol. 2011;47:956-60.

28. Sudbo J, Kildal W, Risberg B, Koppang HS, Danielsen HE, Reith A. DNA content as a prognostic marker in patients with oral leukoplakia. N Engl J Med. 2001;344:1270-8.

29. Goldenberg DM, Rooney RJ, Loo M, Liu D, Chang CH. InVivo fusion of human cancer and hamster stromal cells permanently transduces and transcribes human DNA. PLoS One. 2014;9:e107927.
30. Goldenberg DM, Zagzag D, Heselmeyer-Haddad KM, Berroa Garcia LY, Ried T, Loo M, et al. Horizontal transmission and retention of malignancy, as well as functional human genes, after spontaneous fusion of human glioblastoma and hamster host cells in vivo. Int J Cancer. 2012;131:49-58.

31. Das SN, Khare P, Patil A, Pandy RM, Singh MK, Shukla NK. Association of DNA pattern of metastatic lymph node with disease-free survival in patients with intraoral squamous cell carcinoma. Indian J Med Res. 2005;122:216-23.

32. Oya R, Ikemura K. Can flow cytometrically determined DNA ploidy and S-phase fraction predict regional metastasis in squamous cell carcinoma of the oral cavity? Head Neck. 2003;2:136-42.

33. Saiz-Bustillo R, Corchero-Martin G, Garcia-MontesinosPerea B, Gonzalez-Teran T, Sanchez-Santolino S. Oral squamous cell carcinoma. Cytometric parameters of prognostic interest. Med Oral Patol Oral Cir Bucal. 2005; 10:462-7

34. Danielsen HE, Pradhan M, Novelli M. Revisiting tumour aneuploidy-the place of ploidy assessment in the molecular era. Nat Rev Clin Oncol. 2016;13:291-304.

35. Kusama H, Shimoda M, Miyake T, Tanei T, Kagara N, Naoi Y, et al. Prognostic value of tumor cell DNA content determined by flow cytometry using formalin-fixed paraffin-embedded breast cancer tissues. Breast Cancer Res Treat. 2019;176:75-85.

36. van Zyl AW, van Heerden MB, Langenegger E, van Heerden WF. Correlation between dysplasia and ploidy status in oral leukoplakia. Head Neck Pathol. 2012; 6:322-7.

37. Coley HM, Sargent JM, Titley J, Taylor CG. Lack of prognostic significance of ploidy and S-phase measurements in advanced ovarian cancer. Anticancer Res. 1999;19:2111-6.

38. Zahran AM, Fakhry H, Hussein KA, Abd El-Salam M, Mohamed MA, Tohamy SM, et al. Flow cytometry analysis of DNA ploidy and S-phase fraction in salivary gland tumors of Egyptian patients. Clin Oncol. 2018;3:1393-8.

39. Horii A, Yoshida J, Sakai M, Okamoto S, Kubo T. Flow cytometric analysis of DNA content and Ki-67 positive fractions in the diagnosis of salivary gland tumors. Eur Arch Otorhinolaryngol. 1998;255:265-8.

40. El-Deftar MF, El-Gerzawi SM, Abdel-Azim AA, Tohamy SM. Prognostic significance of ploidy and S-phase fraction in primary intraoral squamous cell carcinoma and their corresponding metastatic lymph nodes. J Egy Nat Cancer Inst. 2012;24:7-14. 